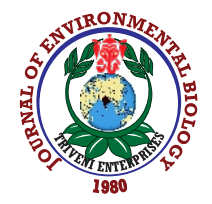

\title{
Host suitability and differential performance parameters of cotton mealybug, Phenacoccus solenopsis for resistance in fibre crop, kenaf genotypes
}

\author{
S. Satpathy ${ }^{1 *}$, B.S. Gotyal', N. M. Alam ${ }^{2}$ and V. Ramesh Babu' \\ 'Division of Crop Protection, ICAR-Central Research Institute for Jute and Allied Fibers, Barrackpore-700 121, India \\ ${ }^{2}$ AINPNF Section, ICAR-Central Research Institute for Jute and Allied Fibers, Barrackpore-700 121, India \\ *Corresponding Author Email : satp1@rediffmail.com
}

\section{Abstract}

Aim: To enumerate resistance in Kenaf (fibre crop) genotypes with distinct host suitability, biological performance and growth parameters of mealybug, Phenacoccus solenopsis Tinsley.

Methodology: Laboratory and glasshouse experiments were conducted to assess the host suitability and resistance of genotypes on the basis of relative colonization, growth and survival in terms of establishment rate and nymphal duration of mealybug.

Results: The wild accession, WHIJ 50 belonging to Hibiscus spp. and the variety JRM 3 of $H$. cannabinus recorded significantly lowest female establishment rate, instantaneous population increase, nymphal survival and growth index with longer nymphal duration possessing possible antixenosis- and antibiosis- mediated resistance. On the other extreme the susceptible genotype, WHIN 47 ( $H$. acetocella) proved favourable for crawler developmental parameters.

Interpretation: The level, mechanism and basis of resistance in kenaf enumerated from this study may pave the way for creating vigorous kenaf hybrids resistant to cotton mealybug.

Key words: Antixenosis, Cotton mealybug, Fiber crop, Host suitability, Kenaf, Resistance

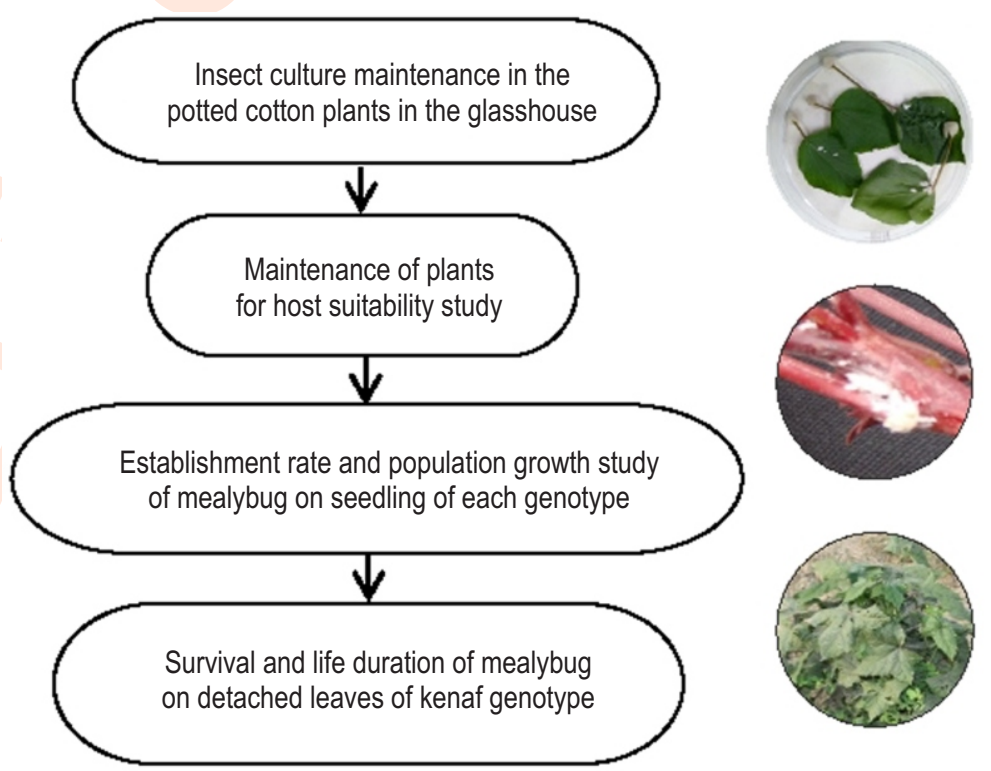




\section{Introduction}

Kenaf, Deccan hemp (Hibiscus cannabinus L: Malvaceae) is a hardy, bast fibre yielding industrial crop grown in India and other Asian countries mainly for fibre. It is a biodegradable, lignocellulosic natural fibre, used in sackings and hessian for bulk packaging, home furnishing, geotextiles, paper pulp, composites and cellulosic biofuel (Satya et al., 2013). Recent findings have designated it as a multi-purpose crop due to its array of industrial applications (Falasca et al., 2014). Kenaf fibre is an excellent source for fabrics, building materials, bedding materials, oil absorbent etc. (Alexopoulou, 2015). The presence of bioactive compounds including tannins, saponins, alkaloids, fatty acids, phospholipids, tocopherols and phytosterols has widened its industrial use (Mohamed et al., 1995). A new application of its leaf powder as food additive that enhances the availability of calcium and fibre has been recorded (Alexopoulou, 2015). Improved cultivation of this crop with integrated input and resources has every probability of raising the return from marginal soils. This further ensures the income of small and marginal farmers by opening the avenues for diversified export-oriented products. However, as a cultivated crop, it suffers from the damage of many pests, most important of which is mealybug.

Although mealybugs of different species have been reported in kenaf, in recent years the infestation of invasive cotton mealybug, Phenacoccus solenopsis Tinsley (Hemiptera: Pseudococcidae) has been reported to cause regular damage inflicting loss in productivity and quality of fibre (Satpathy et al., 2010; Satpathy et al., 2013). The pest status of cotton mealybug is due to several factors. Firstly, the pest is exacerbated by dry and warm condition, when it multiplies very fast and the farmers mostly rely on broad-spectrum insecticides which are highly disruptive to natural enemies (Tertuliano et al., 1993). Besides, the capacity of insect to utilize diverse host plants, i.e., crops to weeds, high fecundity, adaptation to temperature and insecticide resistance facilitates the invasiveness and pest status. (Hao-Jie et al., 2019). Mealybugs feed by sucking the plant sap, causing leaf senescence, pre-mature leaf fall as well as shortened plant height and even plant death (Culik and Gullan, 2005). Damage of cotton mealybug, $P$. solenopsis Tinsley causes loss in productivity and quality of kenaf fibres. In view of repeated failure of insecticidal approach for managing mealy bugs, host plant resistance is the ideal approach in preventing crop yield loss due to mealybug in kenaf (Satpathy et al., 2013). However, measuring resistance is seldom straightforward, and many different approaches are being used, thus affecting biological interpretations. Choosing an appropriate measure for plant resistance is essential for engineering future varieties for improved plant production security, with less dependence on chemical pesticides (Stenberg and Muola, 2017).

As kenaf is a relatively new host of cotton mealybug, it is very important to study the eventual degree of resistance to mealybug amongst the selected varieties and accession of wild species. One of the best way for reinforcing the impact of other tools of IPM like selecting varieties which are relatively unfavourable for the proliferation of pest. This strategy not only limits the reproduction of pest, but also lengthens the growth period facilitating directly suppressing the population build up as well as predation by natural enemies (Tertuliano et al., 1993). For the acceptance of host plant by an insect herbivore, there must be an attraction by the host plant for feeding and the insect must grow, complete its development in the plant on to new progeny (Schoonhooven et al., 2005). Hence, to find out the resistant variety/germplasm, comparative resistance was studied by investigating various antixenosis and antibiosis parameters on the basis of relative establishment and growth of cotton mealybug on selected genotypes consisting of released varieties and wild germplasm of kenaf.

\section{Materials and Methods}

Insect culture: Mealybug cultures were maintained in the potted cotton plants in the glasshouse of ICAR-Central Research Institute of Jute and Allied Fibres, (CRIJAF) Barrackpore, India. Ovisac producing females were collected from the stock of mealybug population. In laboratory, neonate crawlers emerging from such ovisacs were drawn through a fine brush under 10x magnifying glass for use in all the experiments.

Maintenance of plants for the study: The seeds of kenaf genotypes used in the study were collected from the gene bank of ICAR-CRIJAF, Barrackpore, India. Seven released varieties (AMC 108, JBM 81, JRM 3, JRM 5, MT 150, JBM 2004 D and HC583) of Hibiscus cannabinus along with 2 wild accessions, i.e., WHIN-47 (Hibiscus acetocella) and WHIJ-50 (Hibiscus spp.) were evaluated for resistance against mealybug. The seedlings were grown singly in plastic pots $(10 \mathrm{~cm}$ upper diameter, $7.5 \mathrm{~cm}$ lower diameter, and $10 \mathrm{~cm}$ height) filled with soil, sand and FYM (6:2:2).

Establishment rate and population growth study: To enumerate plant resistance, nine genotypes were evaluated under glasshouse conditions $\left(28 \pm 2^{\circ} \mathrm{C}\right.$ temp, $\left.75 \pm 5 \% \mathrm{RH}\right)$ for relative host suitability based on establishment rate, crawler development and instantaneous growth rate of mealybug population. Twenty crawlers of mealybug were released on the terminal leaf of each 25-day-old kenaf seedling of each variety/accession in completely randomised design of experiment. The unit of twenty crawlers per seedling as treatment was replicated six times. Twenty collected crawlers after counting were transferred on to a fresh mealybug-free kenaf leaf. After 30 min when the crawlers settled in the lower leaf surface, individual leaf was placed over the first expanded leaf of each kenaf seedling. The infested leaf was attached to the plant with the help of plastic U-clip. Within 1-2 days, the crawlers from individual leaf settled in the topical part of each kenaf seedlings. To prevent the climbing of ants, other arthropods, and mealybugs on plants, entomological glue (Reliable Corporation, Chennai, India) was applied around the stem at the base of each seedling.

The seedlings were kept at sufficient spacing to restrict the inter-plant crawler movement. The observation was recorded on number of females established (15 days after release), 
crawlers produced by the established females per plant 21 days after release. The establishment rate was calculated 15 days after the release of crawlers by the ratio of number of females present on the seedlings and the number of crawlers initially released per plant (Oliveira et al., 2014). The mealybug crawlers (offspring from established female) on leaves and stem of each genotype were counted under stereo-microscope (Leica S6D, Germany). The number of F1 insects (mealybugs produced by established females) was counted after 21 days, and the instantaneous rate of increase was calculated according to the modified methodology of Stark and Bank, 2003 as given below.

$$
\text { Instantaneous rate of increase } \left.(\mathrm{ri})=\ln \left(\mathrm{N}_{\mathrm{f}} / \mathrm{N}_{0}\right) / \Delta \mathrm{t}\right)
$$

Where $\mathrm{In}=$ natural logarithm, $\mathrm{N}_{\mathrm{f}}=$ final number of observed crawlers, $N_{0}=$ initial number of crawlers released, $\Delta t=$ duration from crawler release to count of F1 crawlers.

Survival and life duration study: Survival, developmental duration and growth index of mealybug was assessed on nine kenaf genotypes. For each genotype, detached topical leaves of 25-day-old potted plants with petiole tips wrapped in wet adsorbent cotton were placed underside up in Petri dish $(9 \mathrm{~cm}$ dia) on water-soaked 2-layer filter paper. In each Petri dish, 20 neonate mealybug crawlers were released on 2 uniform leaves (10 in each leaf). Petri dishes along with insects were incubated in a BOD incubator (Indo-Scientific Surgicals, OVFU $囚$, O-CIS$12 \mathrm{D}$, India) set at $28^{\circ} \mathrm{C} \pm 1^{\circ} \mathrm{C}$. Treatment constituted twenty mealybugs on the leaves of each kenaf genotype replicated six times. Mealybugs on the leaves inside the Petri dishes were examined daily using a stereo-microscope (Leica S6D, Germany). Daily mortality was recorded and survival in each replicate was determined as percentage of surviving individuals. Observation on survival and different stages of nymphal development were recorded; fresh leaves of respective treatments were replaced at 3 days interval. Growth index was calculated according to Raulston (1975).

Statistical analysis: The establishment rate, average number of female per plant, survival percent and nymphal duration of female on different genotypes were subjected to ANOVA through COSTAT followed by Duncan Multiple Range Test $(P=0.05)$ for mean comparison. The significance of differences between treatments was measured by F-test at $P=0.05$.

\section{Results and Discussion}

After 15 days of plant infestation with neonate crawlers, there was a highly significant difference in host suitability exhibited by the number of developed females on the kenaf varieties/accessions ( $F=29.8 ; P<0.001)$. Specifically, the number of female mealybugs was significantly high (11.00 per plant) in WHIN 47 (H. acetocella) indicating higher preference (Table 1). The mean females per plant data indicated that accession, WHIJ 50 belonging to Hibiscus spp. had significantly least (2.77) number of adult females (DMRT, $P<0.05$ ). The mean establishment rate of mealybug which is indicative of the proportion of crawlers developing into adult females on the kenaf genotypes (varieties/accessions) showed a significant difference $(F=29.3 ; \quad P<0.001)$. The establishment rate of insect was significantly low, i.e., 0.14 and 0.22 in WHIJ 50 and JRM 3, respectively (DMRT, $\mathrm{P}<0.05)$. WHIN $47(H$. acetocella) proved favourable for crawler development in the kenaf seedlings with significantly high establishment rate (DMRT, $P<0.05)$.

There was highly significant difference in crawlers produced by the established females on kenaf varieties and accession ( $F=76.3 ; P<0.001)$. As other growth parameters, the number of offsprings from the established female mealybugs in each plant was significantly high in JBM 81 (DMRT, $P<0.05$ ) at par with WHIN 47 and HC 583. The wild accession, WHIJ 50 proved to be least suitable for multiplication of mealy bug that recorded significantly lowest number of crawlers per plant (DMRT, $P<0.05$ ). The instantaneous rate of increase of mealybug population showed significant variation among the kenaf genotypes ( $F=90.1$; $\mathrm{P}<0.001)$, among which this parameter was significantly lowest in WHIJ 50 (0.14) followed by JRM 3 (0.18) (DMRT, P<0.05) (Fig. 1). The life duration and survival rate of mealybug crawlers and nymph (female) reared in the laboratory on the detached leaf of kenaf genotypes indicated significant variation $(F=7.07 ; P<0.001$

Table 1: Mean female per plant, crawler per plant and establishment rate of $P$. solenopsis on seedlings of different kenaf varieties and accessions

\begin{tabular}{llll}
\hline Genotypes & Female per plant & Crawler per plant & Establishment rate \\
\hline AMC 108 (Hc) & $8.11 \pm 0.60^{\mathrm{C}}$ & $840.72 \pm 15.11^{\mathrm{B}}$ & $0.41 \pm 0.03^{\mathrm{C}}$ \\
JBM 81 (Hc) & $9.78 \pm 0.52^{\mathrm{AB}}$ & $927.06 \pm 30.42^{\mathrm{A}}$ & $0.49 \pm 0.03^{\mathrm{AB}}$ \\
JRM 3 (Hc) & $4.39 \pm 0.49^{\mathrm{F}}$ & $401.85 \pm 28.67^{\mathrm{E}}$ & $0.22 \pm 0.02^{\mathrm{F}}$ \\
JRM 5 (Hc) & $6.44 \pm 0.53^{\mathrm{DE}}$ & $474.23 \pm 37.02^{\mathrm{E}}$ & $0.32 \pm 0.03^{\mathrm{DE}}$ \\
MT 150 (Hc) & $7.53 \pm 0.50^{\mathrm{CD}}$ & $632.08 \pm 44.27^{\mathrm{D}}$ & $0.38 \pm 0.02^{\mathrm{CD}}$ \\
JBM 2004 D (Hc) & $6.09 \pm 0.38^{\mathrm{E}}$ & $732.31 \pm 35.14^{\mathrm{C}}$ & $0.31 \pm 0.02^{\mathrm{E}}$ \\
HC-583 (Hc) & $8.66 \pm 0.25^{\mathrm{BC}}$ & $884.01 \pm 33.37^{\mathrm{AB}}$ & $0.43 \pm 0.01^{\mathrm{BC}}$ \\
WHIN 47 (Ha) & $11.00 \pm 0.57^{\mathrm{A}}$ & $925.97 \pm 19.52^{\mathrm{AB}}$ & $0.55 \pm 0.03^{\mathrm{A}}$ \\
WHIJ 50 (Hsp.) & $2.77 \pm 0.30^{\mathrm{G}}$ & $190.55 \pm 10.33^{\mathrm{F}}$ & $0.14 \pm 0.01^{\mathrm{G}}$ \\
LSD (p =0.05) & 1.35 & 85.67 & 0.07 \\
\hline
\end{tabular}

Hc- Hibiscus cannabinus, Ha- Hibiscus acetocella, Hsp.- Hibiscus species (species not yet identified). Values are mean \pm SEM 
Table 2: Mean survival, durations pre-imaginal development (crawler to adult) and growth index of $P$. solenopsis cumulative on detached leaf of different kenaf varieties and accessions

\begin{tabular}{llll}
\hline Genotype & Survival (\%) & Female duration (days) & Growth index \\
\hline AMC 108 (Hc) & $62.35{ }^{*}(52.16 \pm 2.31)^{\mathrm{ABC}}$ & $17.89 \pm 0.63^{\mathrm{CD}}$ & $2.94 \pm 0.19^{\mathrm{AB}}$ \\
JBM 81 (Hc) & $71.60(57.84 \pm 1.73)^{\mathrm{A}}$ & $17.01 \pm 0.84^{\mathrm{D}}$ & $3.42 \pm 0.10^{\mathrm{A}}$ \\
JRM 3 $(\mathrm{Hc})$ & $46.05(42.78 \pm 2.48)^{\mathrm{DE}}$ & $21.15 \pm 0.43^{\mathrm{AB}}$ & $2.03 \pm 0.13^{\mathrm{DE}}$ \\
JRM 5 $(\mathrm{Hc})$ & $46.20(42.82 \pm 4.76)^{\mathrm{DE}}$ & $18.10 \pm 0.72^{\mathrm{CD}}$ & $2.35 \pm 0.20^{\mathrm{CD}}$ \\
MT 150 (Hc) & $50.90(45.52 \pm 1.77)^{\mathrm{CD}}$ & $19.64 \pm 0.55^{\mathrm{BC}}$ & $2.33 \pm 0.10^{\mathrm{CD}}$ \\
JBM 2004 D (Hc) & $54.69(47.65 \pm 2.97)^{\mathrm{BCD}}$ & $17.98 \pm 0.76^{\mathrm{CD}}$ & $2.65 \pm 0.11^{\mathrm{BC}}$ \\
HC-583 (Hc) & $66.71(54.8 \pm 3.52)^{\mathrm{AB}}$ & $16.54 \pm 0.86^{\mathrm{D}}$ & $3.39 \pm 0.37^{\mathrm{A}}$ \\
WHIN 47 (Ha) & $71.24(57.59 \pm 1.95)^{\mathrm{A}}$ & $17.77 \pm 0.58^{\mathrm{CD}}$ & $3.27 \pm 0.19^{\mathrm{A}}$ \\
WHIJ 50 (Hsp.) & $37.43(37.71 \pm 0.65)^{\mathrm{E}}$ & $23.30 \pm 0.74^{\mathrm{A}}$ & $1.64 \pm 0.07^{\mathrm{E}}$ \\
LSD $(p=0.05)$ & 7.70 & 1.97 & 0.52 \\
\hline
\end{tabular}

Values are mean \pm SEM, *Figures in the parentheses are arcsine transformed values

and $F=9.42 ; P<0.001)$. The kenaf genotypes tested for host suitability, which exhibited significant negative effect on survival of crawlers and nymphs on the wild accession were WHIJ 50; cultivated varieties, JRM-3 and JRM-5 (37.71 to 42.82) (37.43 to $46.05 \%$ ) (DMRT, $P<0.05$ ) that indicates manifestation of maximum antibiosis on immature stages reared on the detached leaf from the respective plants (Table 2).

On the other extreme, the survival of mealy bug was more in the wild accession, WHIN 47; cultivated varieties, JBM-81, AMC-108 and HC-583 (52.16 to 57.84) (62.35 to 71.60\%) (DMRT, $P<0.05)$. The developmental period of immature stages (crawler and nymph) on various host plants varied from 16.54 to 23.30 days. The wild accession, WHIJ 50 and variety JRM 3 significantly prolonged the growth period of immature stages developed into female ( 23.30 and 21.15 days) (DMRT, $P<0.05$ ) as compared to the varieties of cultivated species and another wild accession of
H. acetocella (16.54 to 19.64 days). Significant effect of host plants was exhibited on the growth index of mealybug reared on different genotypes $(F=12.10, P<0.001)$. Kenaf varieties, JBM 81, HC583 and the wild accession WHIN47 were assumed to be more susceptible with significantly higher growth index (3.27 to 3.42) (DMRT, $P<0.05$ ). As reflected on other performance parameters, the growth was significantly lowest (1.64) on the wild accession WHIJ 50 (DMRT, $\mathrm{P}<0.05$ ). Our study reflects that seven kenaf varieties (Hibiscus cannabinus) and two wild germplasm accessions (one each of Hibiscus acetocella and Hibiscus spp.) demonstrated variable degree of host suitability for $P$. solenopsis. Following the release of crawlers on these tested kenaf lines, there was a significant difference in the rate of female establishment, the number of progeny crawlers from the established females, were the parameters indicative of suitability of plants as host for proper growth and multiplication of mealybug. Significantly least number of females could develop with the

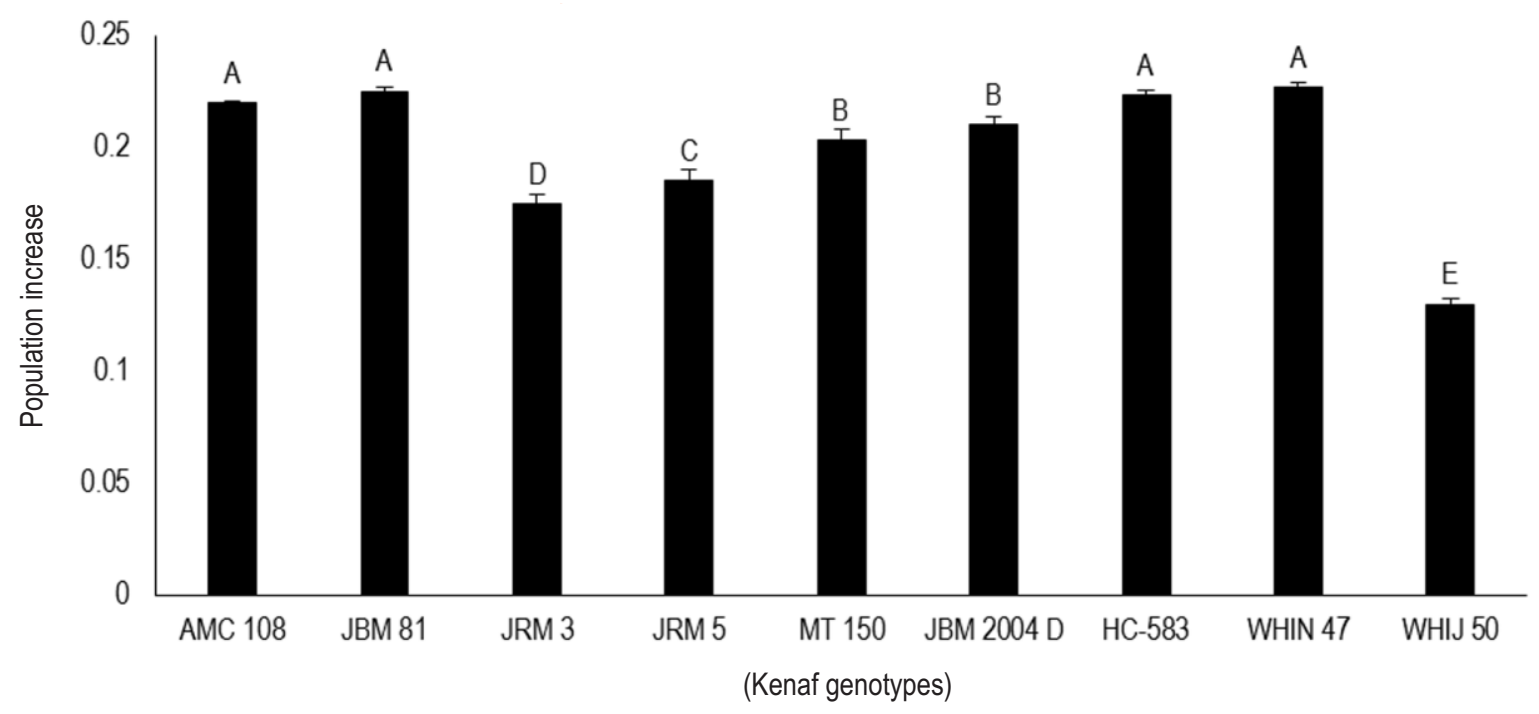

Fig. 1: Instantaneous rate of mealybug population increase on different kenaf genotypes. 
lowest establishment rate on the wild accessions, WHIJ 50 belonging to Hibiscus spp. and the variety JRM 3 of $H$. cannabinus (DMRT, $P<0.05$ ). On the other extreme, WHIN 47 $(H$. acetocella) proved favorable for crawler development in kenaf seedlings with a significantly high establishment rate (DMRT, $P<0.05$ ). Parallel to such findings, the net reproductive rate, intrinsic rate of natural increase, and biotic potential and mean relative growth rate of $P$. solenopsis female were significantly different on the tested plants which point towards the definite role of host plants belonging to different species in regulating the population of $P$. solenopsis (Dogar et al., 2018; Nagrare et al., 2018) which influences the development and reproduction of $P$. solenopsis (Xin et al., 2012).

Cotton mealybug was able to develop and reproduce on all the genotypes of wild and cultivated kenaf species, however, the extent of such activities differed. Indeed, significant reduction in population establishment and growth of $P$. solenopsis in the resistant accession, WHIJ 50 and reverse on a susceptible line such as WHIN $47(H$. acetocella), were associated with antixenosis and antibiosis due to relative degree of nonpreference and adverse effect on biology. Antixenosis or nonpreference affects insect behavior by deterring or reducing the colonization process whereas, antibiosis affects insect lifehistory traits (survival, development, and fecundity) (Panda and Khush, 1995). In this study, few varieties and accessions of different kenaf species manifested the antibiosis against mealybug; particularly causing adverse effects on duration and survival rate of mealybug crawlers and nymph and the growth index (Table 2). The accession, WHIJ-50, and variety JRM -3 negatively influenced the survival, life duration, and growth index to a greater extent which pointed out the relative degree of resistance against cotton mealybug. Previous studies indicate that antibiosis resistance of cassava to mealybug is linked to increased level of phenolic compounds. The extent of phenolic level in leaves appears to be a good indicator or prediction as to whether a cassava variety is resistant or susceptible to mealybug infestation (Calatayud et al., 1994; Tertuliano et al., 1999). The host plant plays an important role in regulating insect population and biology as the concentration and proportion of nutrients differ greatly among species (Slanskyand Rodriquez, 1987; Schoonhoven et al., 2005). Chemical barriers not only include antifeedant or repellent compounds to prevent colonization but also toxic compounds that delay or prevent increase in insect population (Smith and Clement, 2012). The negative effect of phenolics on the biology of the mealybug exerts the defence mechanism of cotton plant against mealybug reveals that phenol content was higher in resistant cultivars (Ghule et al., 2011). However, some compounds such as sugars and amino acids stimulate feeding activity in insects (Uthamasamy et al., 1971). The physiological activity of plants and resistance against insect pests largely depend on the nutrient composition (Hu et al., 2010). Shahid et al. (2017) reported that sugar concentration also affects the attraction of $P$. solenopsis to host, which is positively associated with total soluble sugars (Shahid et al., 2017).
Exploitation of plant defences to breed resistant variety is one of the novel components of integrated pest management programs, which minimizes insect damage. Unlike other crops, the presently cultivated kenaf varieties substantially lack resistance against mealybug, which is emerging as a new problem under changing climatic conditions. This study revealed considerable resistance in the wild genotype WHIJ 50 and the cultivated variety JRM 3 . In the case of insects, possessing multiple overlapping short life stages on short-duration crops, restriction of colonization caused by antixenosis and reduction of population size mediated by antibiosis are equally important. (Stenberg and Muola, 2017). This theory also fits well for kenaf and mealybug as it is a short duration crop and mealybug has overlapping generations due to faster growth. A previous study established that through wide hybridization between different kenaf species it is possible to transfer useful genes from wild to elite cultivated varieties (Satya, 2013). In that direction, the outcome of this study brought out the relative resistance levels of the kenaf genotypes and may pave the way for creating and producing vigorous hybrids that would display satisfactory resistance to mealybug infestation.

\section{Acknowledgment}

The authors are highly grateful to the Director, ICARCentral Research Institute for Jute and Allied Fibres, Barrackpore-700121, West Bengal, India for providing facilities to conduct the experiments for this study.

\section{Add-on Information}

Author' contribution: S. Satpathy: Conceptualization, experiment execution, manuscript preparation; B.S. Gotyal: Experiment execution, data collection; N. M. Alam: Data analysis; V. Ramesh Babu: Data collection, Experiment execution.

Research content: The research contents is original and has not been published elsewhere

\section{Ethical approval: NotApplicable}

Conflict of interest: The authors declare that there is no conflict of interest.

\section{Data from other sources: NotApplicable}

Consent to publish: All authors agree to publish the paper in Journal of Environmental Biology.

\section{References}

Alexopoulou, E., D. Lib, Y. Papatheohar, H. Siqi, D. Scordia and G. Testam: How kenaf (Hibiscus cannabinus L.) can achieve high yields in Europe and China. Ind. Crops Prod., 64, 131-140 (2015).

Calatayud, P. A., Y. Raheb, B. Delobel, F. Khuong-Huu, M. Tertuliano and $B$. Le Ru: Influence of secondary compounds in the phloem sap of cassava on expression of antibiosis towards the mealybug, Phenacoccus manihoti. Entomol. Exp. Appl., 72, 47-57 (1994). 
Culik, M.P. and P.J. Gullan: A new pest of tomato and other records of mealybugs (Hemipreta: Pseudococcidae) from Espírito Santo, Brazil. Zootaxa, 964, 1-8 (2005).

Dogar, A.M., M.N. Ayyaz, S.A. Shad and A. Naeem: Effect of host plants on life history traits of Phenacoccus solenopsis (Homoptera: Pseudococcidae). Int. J. Trop. Insect Sci., 38, 387-393 (2018).

Falasca, S.L., A.C. Ulberich and S. Pitta-Alvarez: Possibilities for growing kenaf (Hibiscus cannabinus L.) in Argentina as biomass feedstock under dry-sub humid and semi-arid climate conditions. Biomass Bioenerg., 64, 70-80 (2014).

Ghule, S.R., U.P. Barkhade, M.P. Moharil and T.B. Ugale: Biochemical basis of resistance to cotton cultivars against mealybugs (Phenococcus solenopsis Tinsley). Crop Res. (Hisar), 42, 320-323 (2011).

Hao-Jie, T., A.O. Yan, L.I. Zi-hao, W. Ying and J. Ming-Xing: Invasion biology of the cotton mealybug, Phenacoccus solenopsis Tinsley: Current knowledge and future directions. J. Integ. Agril., 18, 758-770 (2019).

Hu, J.S., D.B. Gelman, M.E. Salvucci, Y.P. Chen and M.B. Blackburn: Insecticidal activity of some reducing sugars against the sweet potato whitefly, Bemisia tabaci, Biotype B. J. Insect Sci., 10, 203 doi: 10.1673/031.010.20301 (2010).

Mohamed, A., H. Bhardwaj, A. Hamama and C. Webber III: Chemical composition of kenaf (Hibiscus cannabinus L.) seed oil. Ind. Crops Prod., 4, 157-165 (1995).

Nagrare, V., B. Naikwadi, V. Deshmukh and S. Kranthi: Biology and population growth parameters of cotton mealy bug, Phenacoccus solenopsis Tinsley (Hemiptera: Pseudococcidae) on five host plant species. Anim. Biol., 68, 333-352 (2018).

Oliveira, M.D., C.S.A. Silva-Torres, J.B. Torres and J.E.M. Oliveira: Population growth and within-plant distribution of the striped mealybug, Ferrisia virgata (Cockerell) (Hemiptera, Pseudococcidae) on cotton. Rev. Bras. Entomol., 58, 71-76 (2014).

Panda, N. and G.S. Khush: Host Plant Resistance to Insects. CAB International, Wallingford, UK (1995).

Raulston, J.R.: B-Vitamin supplements required for soy flour-wheat germ diet used in rearing tobacco bud worm. Ann. Entomol. Soc. America., 68, 387-388 (1975).

Satpathy, S., B. S. Gotyal, T. Ramasubramanian and K. Selvaraj: Mealybug, Phenacoccus solenopsis Tinsley infestation on jute (Corchorusolitorius) and mesta (Hibiscus sabdariffa). Insect Environ., 19, 187-188 (2013).

Satpathy, S., T. Ramasubramanian, B.S. Gotyal, S.K. Bhattacharya and
S.K. Laha: Evaluation of seed treating and foliar insecticides against kenaf mealybugs, Phenacoccus solenopsis (Tinsely) (Hemiptera: Pseudococcidae). Proceedings of the National Symposium on "Emerging Trends in Pest Management Strategies under Changing Climatic Scenario" held during 20-21 December, 2010 at Department of Entomology, Orissa University of Agriculture and Technology, Bhubaneshwar, Odisha, pp. 92-93 (2010).

Satya, P., M. Karan, C.S. Kar, J. Mitra, D. Sarkar. P.G. Karmakar, M. K. Sinha and B.S. Mahapatra: Development and molecular characterization of interspecific hybrids of Hibiscus cannabinus and $H$. radiatus. Indian. J. Biotech., 12, 343-349 (2013).

Schoonhoven, L.M., J.J.A. van Loon and M. Dicke: Insect Plant Biology. Oxford. Oxford University Press, $421 \mathrm{p}$ (2005).

Shahid, M.R., M.J. Arif, M.D. Gogi and N. Javed: Host-plant-preference and mortality analysis of Phenacoccus solenopsis in association with biochemical traits of different plant species. Int. J. Agric. Biol., 19, 211-218 (2017).

Slansky, Jr. F. and J.G. Rodriquez: Nutritional ecology of insects, mites, spiders, and related Invertebrates. John Wiley \& Sons, Inc., New York, New York, USA, pp. 1016 (1987).

Smith, C.M. and S.L. Clement: Molecular bases of plant resistance to arthropods. Annu. Rev. Entomol., 57, 309-328 (2012).

Stark, J.D. and J.E. Banks: Population-level effect of pesticides and other toxicants on arthropods. Annu. Rev. Entomol., 48, 505-519 (2003).

Stenberg, J.A. and A. Muola: How should plant resistance to herbivores be measured? Front. Plant Sci., 8, 663 (2017). doi: 10.3389/ fpls. 2017.00663

Tertuliano, M., P.A. Calatayud and B. Le Ru: Seasonal changes of secondary compounds in the phloem sap of cassava in relation to fertilisation and to infestation by the cassava mealybug. Insect Sci. Applic., 19, 91-98 (1999).

Tertuliano, M., S. Dossou-Gbete and B. Le Ru: Antixenotic and antibiotic components of resistance to the cassava mealybug, Phenacoccus manihoti (Homoptera: Pseudococcidae) in various host-plants. Insect Sci. Applic., 14, 657-665(1993).

Uthamasamy, S., S. Jayaraj and T.R. Subramaniam: Studies on the varietal resistance of bhendi, Abelmoschus esculentus $(L)$ to the leafhopper, Amrasca devastans (Dist.) (Homoptera: Jassidae). South Ind. Hortic., 19, 53-59 (1971).

Xin, G., L.U. Yongyue and Z. Ling: Study on developmental durations and fecundity of Phenacoccus solenopsis Tinsley on four species of hosts. Agril. Sci. Technol., 13, 408-411(2012). 